ANTONIO SANJUÁN PÉREZ NATALIA QUINTAS FROUFE SANDRA MARTÍNEZ COSTA

TABVERTISING FORMATOS Y ESTRATEGIAS PUBLICITARIAS EN TABLETAS

圆

(ิ) EDITORIAL UOC

Tabvertising. Formatos y estrategias publicitarias en tabletas

Antonio Sanjuán Pérez, Natalia Quintas Froufe y

Sandra Martínez Costas

Editorial Fórum XXI, Madrid

\title{
Exploración de nuevos soportes digitales. Tadvertising como oportunidad para la creatividad publicitaria
}

I libro que a continuación presento aborda la realidad del tabvertising como - fenómeno de comunicación publicitaria. Elaborado por los doctores de la Universidad de A Coruña, Antonio Sanjuán Pérez, Natalia Quintas Froufe y Sandra Martínez Costa el texto muestra novedosos formatos y estrategias de comunicación nacidas al amparo de las nuevas tecnologías de la comunicación gracias a un profundo análisis de la realidad publicitaria digital actual. De este modo, este libro se convierte en una importante aportación dentro de los estudios vinculados a los dispositivos móviles y tabletas.

El texto se presenta distribuido en cuatro capítulos que profundizan en las posibilidades comunicacionales de las tabletas digitales a través de la fórmula específica del tabvertising. A través de una panorámica del mercado actual de las tabletas y enfatizando tanto en aspectos técnicos como sociológicos, los autores muestran el potencial de estos dispositivos móviles para la difusión de mensajes de carácter persuasivo. Realizando un análisis exhaustivo de sus peculiaridades exponen el porqué de que estos dispositivos se hayan convertido actualmente en un inte- 
resante soporte publicitario para agencias y anunciantes, gracias al crecimiento exponencial del mercado de telefonía móvil y las tabletas, así como del desarrollo de una tecnología muy atractiva y apreciada por los usuarios del siglo XXI.

Ahondando en este campo de estudio, los autores ponen énfasis en las fórmulas y contenidos digitales específicos generados ad hoc para este soporte móvil. A través de diversos ejemplos reales, repasan los diferentes formatos publicitarios que tienen lugar en torno a esta pantalla, tanto aquellos que derivan de otros medios como los específicos para tabletas (In-App Ads).

Dentro de este ámbito tecnológico, han incluido un apartado donde revisan el concepto de brand content poniendo de relevancia la importancia de generar experiencias únicas a los consumidores y haciendo hincapié en la necesidad de ofrecer al usuario de estas tabletas productos de ocio, información, o formación cada vez más creativos, elaborados y de mayor calidad. En el énfasis de profundizar en la variedad de formatos de brand content que han surgido como consecuencia de esta necesidad de llamar la atención del público-usuario-consumidor, los autores enumeran y describen detalladamente diferentes formados creados específicamente para las tabletas como el brand entertainment, el storytelling, el brand integration, los webisodios, etc., pero también en aquellas fórmulas nacidas en otros medios y soportes como el product placement (en la TV o el cine), el advergaming (en los videojuegos), el patrocinio, etc. que se adaptan a las características de la publicidad en las tabletas.

Finalmente, los autores plantean diversos casos de éxito de empresas que han llevado sus estrategias de comunicación a las tabletas realizando acciones publicitarias específicas para este soporte. Estos ejemplos reales ponen en valor este libro, ya que ilustran modelos a seguir por profesionales de la comunicación y la publicidad para diseñar campañas en dispositivos móviles, en general, y en tabletas, en concreto.

La relevancia científica de este libro radica en la combinación de la parte teórico-conceptual y su reflejo práctico a través de la muestra de experiencias publicitarias reales que lo convierten en una de las primeras aproximaciones al fenómeno del tabvertising y su modelo de negocio.

ICONO14 | 2015 Volumen $13 \mathrm{~N}^{\circ} 1$ | ISSN: 1697-8293 | DOI: ri14.v13i1.743 
Tomando esta referencia bibliográfica como punto de partida, los estudios acerca de este fenómeno publicitario deben dirigirse hacia el análisis del grado de impacto de sus formatos publicitarios en los usuarios-consumidores, así como establecer la rentabilidad que estos generan a los anunciantes para constatar el grado de eficacia tanto de carácter cualitativo (notoriedad-imagen de marca) como cuantitativo (beneficio para el anunciante).

Los soportes digitales; un campo para la nueva comunicación publicitaria.

Patricia Comesaña Comesaña

Doctora en Publicidad, Relaciones Públicas y Comunicación Audiovisual por la Universidad de Vigo / Creativa publicitaria print13@hotmail.com

DOI: ri14.v13i1.743 | ISSN: 1697-8293 | Año 2015 Volumen 13 Nº 1 | ICONO14 